\title{
Invited review: Breeding and ethical perspectives on genetically modified and genome edited cattle
}

\author{
S. Eriksson,${ }^{* 1}$ E. Jonas, ${ }^{*}$ L. Rydhmer, ${ }^{*}$ and H. Röcklinsberg† \\ *Department of Animal Breeding and Genetics, Swedish University of Agricultural Sciences, and \\ †Department of Animal Environment and Health, 75007 Uppsala, Sweden
}

\begin{abstract}
The hot topic of genetic modification and genome editing is sometimes presented as a rapid solution to various problems in the field of animal breeding and genetics. These technologies hold potential for future use in agriculture but we need to be aware of difficulties in large-scale application and integration in breeding schemes. In this review, we discuss applications of both classical genetic modifications (GM) using vectors and genome editing in dairy cattle breeding. We use an interdisciplinary approach considering both ethical and animal breeding perspectives. Decisions on how to make use of these techniques need to be made based not only on what is possible, but on what is reasonable to do. Principles of animal integrity, naturalness, risk perception, and animal welfare issues are examples of ethically relevant factors to consider. These factors also influence public perception and decisions about regulations by authorities. We need to acknowledge that we lack complete understanding of the genetic background of complex traits. It may be difficult, therefore, to predict the full effect of certain modifications in large-scale breeding programs. We present 2 potential applications: genome editing to dispense with dehorning, and insertion of human genes in bovine genomes to improve udder health as an example of classical GM. Both of these cases could be seen as beneficial for animal welfare but they differ in other aspects. In the former case, a genetic variant already present within the species is introduced, whereas in the latter case, transgenic animals are generated - this difference may influence how society regards the applications. We underline that the use of GM, as well as genome editing, of farm animals such as cattle is not independent of the context, and should be considered as part of an entire process, including, for example, the assisted reproduction technology that needs to be used. We propose that
\end{abstract}

Received March 31, 2017.

Accepted August 29, 2017.

${ }^{1}$ Corresponding author: susanne.eriksson@slu.se breeding organizations and breeding companies should take an active role in ethical discussions about the use of these techniques and thereby signal to society that these questions are being responsibly addressed.

Key words: genome editing, genetic modification, cattle, ethics, breeding program

\section{INTRODUCTION}

The European Food Safety Authority (EFSA) defines genetic modification (GM) as follows: "Genetic modification of an animal involves altering its genetic material by adding, changing or removing certain DNA sequences in a way that does not occur naturally. It aims to modify specific characteristics of an animal or introduce a new trait, such as disease resistance or enhanced growth" (EFSA, 2017). The generation of transgenic animals implies insertion of DNA sequences from another organism using genetic engineering. It opens up possibilities to introduce traits from other species into farm animals, which could not be done through traditional breeding. For a genetic modification to be inherited, it must be present in the gametes and integrated into a chromosome. In the case of genome editing, no foreign DNA is incorporated in the genome, and there is no consensus on whether genome edited organisms should be referred to as GM (Cotter et al., 2015; Bruce, 2016b; Nuffield Council on Bioethics, 2016). Similar genetic changes may or may not occur naturally in the same species or breed. The classification may be important in the process of obtaining legal approval for applications. For the discussion in this review, however, the preconditions and effects of the genetic changes are more important than the classification of the techniques.

A rapidly increasing number of publications suggest agricultural applications of GM or genome editing of livestock. Modification or editing of animal genomes raises several ethical questions, and societal acceptance of GM animals has been shown to be influenced by both the species modified and whether the animals are to be used for production of food or pharmaceuticals (Frewer 
et al., 2013a,b). Citizen concerns reflect the complex ethical and safety considerations that need to be made by authorities before GM animals and products can be released on the market. Commercialization of GM animal products is a complex matter. The first GM animal for human consumption, the AquAdvantage salmon (AquaBounty Technologies, Maynard, MA), was only recently approved (FDA, 2015), more than a decade after the first attempts of approval. This salmon is produced using classical GM, and there is currently no comparable case of an animal product for human consumption from genome edited animals. Besides the species involved and the perceived importance of the product, the type of technology used and the absence or presence of alternative ways to reach the goal can influence ethical and practical considerations. Farm animal genomes can now be modified without leaving traces of the technology used and with increasing precision and efficiency (Laible et al., 2015), and these are relevant aspects. Even if technical and legal obstacles are settled, ethical issues and practical breeding questions regarding introduction and multiplication of modified or edited genetic variants in the populations will remain. In this process, possible ethical concerns need to be considered. There are probably lessons to be learned from societal reactions to previous attempts to introduce GM in livestock. To prepare for possible reactions to genome editing, early ethical discussions within the scientific and animal breeding community could be valuable.

Most articles about GM farm animals deal with biotechnical developments, but there is increased interest in societal and ethical aspects, too, requiring multidisciplinary approaches (Frewer et al., 2013a). Nevertheless, there is a lack of scientific papers combining deep discussions between animal breeders and ethicists in the author team, which is why we chose an interdisciplinary approach in this review. Most researchers in animal breeding and genetics (including the 3 geneticist authors), appreciate development of methods and techniques that increase efficiency in breeding. We also tend to take already routinely applied inventions for granted and instead direct our focus, and possibly ethical concerns, toward inventions still in the pipeline. For a researcher in ethics (such as the last author), this may seem incomplete. With this article, we want to discuss potential applications of GM and genome editing of cattle for food production considering both the breeding program and its ethical aspects. By choosing this focus, we do not consider all potential ethical concerns on keeping, breeding, and utilizing animals for the benefit of humans. Also, genetic change of livestock through conventional selective breeding and associated assisted reproduction techniques, are artificial and raise ethical questions. In this review, however, we focus on some of the ethically relevant aspects of methods directly linked to the use of GM and genome editing.

We start with a short background on the use of GM and genome editing in livestock, and on assisted reproduction techniques (ART) that enable such genetic changes, followed by possible consequences of applications in breeding schemes. Each part is followed by an ethical reflection. In later sections, we focus on 2 cases: (1) genome editing to eliminate dehorning, and (2) insertion of human genes into bovine genomes to improve udder health. These cases are compared in a general discussion focusing on ethical parameters selected from the sections above, followed by some conclusions.

\section{GENETICALLY MODIFIED AND GENOME EDITED CATTLE}

Several recent review articles have been published about genetic modifications of animals generated by different methods in various species, including cattle. Genetic modifications of cattle have often targeted the udder, aiming for improved udder health or milk quality aspects. Lievens et al. (2015) classified GM animals of 15 species as either food-producing livestock, medical bioreactors, or companion animals. Five out of 6 studies of GM cattle in their review dealt with cattle as livestock, in which improved animal health or milk composition were the goals; only 1 study focused on cattle as bioreactors.

Laible et al. (2015) presented an overview of different methods used on farm animal species: genetic changes of cattle applicable in agriculture have been generated using both genome editing and classical GM techniques such as microinjection, and random or targeted cell-mediated techniques. The development of these methods applicable in cattle for different purposes was further described by Wang (2015). In a recent overview, Tan et al. (2016) presented the background to genome editing in livestock and discussed future applications and challenges for the techniques. Although technical details and comprehensive overviews of GM and genome edited farm animals can be found in other publications, we will discuss here a few specific cases from an interdisciplinary breeding and ethics perspective.

\section{Reproduction Techniques-A Precondition}

The advancements in controlled genetic modifications of farm animals would not have been possible without the development and refinement of ART, including in vitro fertilization, in vitro cultivation of embryos, and cloning techniques. The use of somatic cell nuclear transfer (SCNT) or embryo microinjections, together 
with new methods to modify the genome, made various applications possible, despite the lack of true pluripotent cells in large domestic animals (Petersen and Niemann, 2015). Indeed, SCNT remains the primary method to generate GM and genome edited livestock (Tan et al., 2016). Because in vitro handling of germ cells or embryos are still necessary for controlled genetic engineering of animals, potential ethical concerns associated with methods for the introduction of the modification or the preparation of animals in the process will be a relevant part of the discussion in this article.

In cattle breeding, advanced ART are in place and used on a large scale within conventional breeding programs as important tools to increase genetic progress. The fact that such techniques are already well established would facilitate commercial use of GM or genome edited breeding animals. Artificial insemination has been routinely used in cattle breeding since the 1940s, and multiple ovulation of donors and embryo transfer to recipient females in cattle was developed in the 1970s. Nonsurgical ovum pickup and in vitro fertilization were adapted to cattle in the 1980s and are considered mature reproduction techniques today (van Wagtendonk-de Leeuw, 2006). Soon after the successful cloning of an adult sheep in 1996 (Wilmut et al., 1997), cloning of cattle and other farm animals by SCNT followed. The number of laboratories with expertise in SCNT in cattle increased faster than that for other mammals (Oback and Wells, 2007).

Further development of ART needed for GM and genome editing of animals, such as in vitro cultivation of embryos, has decreased negative effects on development and survival rate of embryos and young offspring. One well-known abnormality affecting especially cattle and sheep fetuses after in vitro cultivation of embryos was large offspring syndrome, where the calf or lamb had considerably increased BW (Kruip and denDaas, 1997). With the development of serum-free culture conditions, large offspring syndrome is no longer a clinical problem in routine in vitro embryo production (Stroebech et al., 2015). Still, SCNT increases the risk of other fetal and placental abnormalities (Hill, 2014). This results in higher than usual losses during different stages of bovine pregnancies and in increased mortality of calves. These problems might be due, in part, to epigenetic modifications of the DNA chain and, as stated in a review by Smith et al. (2015), some of the epigenetic mechanisms and thereby consequences are yet unknown. In spite of these problems, Kues and Niemann (2011) noted that SCNT seems to be more efficient in cattle than in most other mammals. The efficiency needs to improve, however, as rates of embryos resulting in surviving offspring below $10 \%$ are still reported. In a recent study by Gao et al. (2017), using SCNT for genome editing of cattle, the pregnancy rate averaged $25 \%$ for the most successful method used, about one-quarter of the pregnancies resulted in calvings, and only half of the born calves survived the first 3 mo.

\section{Ethical Aspects of the Use of Reproduction Techniques}

The use of advanced ART is still a precondition for GM and genome editing. There are also other important preconditions, such as breeding programs with breeding objectives, that could not easily be achieved using conventional methods, but we focus here on ethical concerns evoked by ART that are often neglected in current discussions on GM or genome editing. Potential problems associated with the use of cloning have been given special attention within the European Union (EU). Ethical and animal welfare concerns brought the European Commission in 2015 to approve 2 proposals from 2013 to restrict cloning of farm animals, resulting in suspension of cloning of animals for food production and marketing of live animal clones, and prohibited food products from animal clones on the EU market (European Commission, 2013). With SCNT, there remain increased risks of failures at in vitro cultivation and transfer of embryos, and during the development in the uterus with risks of abnormalities caused by epigenetic influence (Urrego et al., 2014). This calls for reflection on the human-animal relationship, on the balance between harm and benefit, as well as criteria to justify limitation of animal welfare.

One set of ethical aspects is related to concerns about the individual animal's welfare, considering both the dam and the calf. That the dam is sentient is understood, but when the calf should be regarded as a sentient being is still debated. According to Mellor (2010), a calf is not sentient before it breathes with its own lungs, implying that a fully developed but not yet breathing individual would not be capable of physically experiencing struggle at birth. In contrast to this, the EU's Directive 2010/63/EU on the use of animals in research states that live non-human vertebrates are to be regarded as sentient, and that, based on scientific evidence, fetal forms of mammals are included in this group from the last trimester of pregnancy (recital 9, Chapter 1, Article 1, §3; European Union, 2010). Based on this view, calf welfare is relevant both from ethical and legal points of view and should be taken into consideration in a utilitarian harm-benefit analysis. Cattle breeding procedures used by farmers or breeding companies do not generally need approval by an animal ethics committee. This differs from Article 4 on $3 \mathrm{R}$ (replacement, reduction, refinement) in Directive 2010/63/EU, which states that breeding procedures 
shall undergo the same claim of refinement as other accommodation and care of research animals (European Union, 2010). If breeding were part of a research setting, it would have undergone a project evaluation balancing harm and benefit.

From an animal welfare perspective, there is an increased risk of the unborn calf suffering in later stages in fetal development or from being born with deformations when SCNT is used. For egg donors, hormonal treatments and the ovum pickup process have been shown not to harm reproduction or production (Chastant-Maillard et al., 2003) or to cause stress or pain, although heifers have been shown to react to the administration of epidural anesthesia (Petyim et al., 2007). From a utilitarian point of view, an individual's impaired welfare may be outweighed by other factors, such as breeding achievements appreciated by humans in the next cow generation, but the harm-benefit calculation should be made carefully. Consideration should not be limited, for instance, only to calves born healthy and their health status and overall welfare during the first months of life, but should also include less successful pregnancies, related welfare issues, and financial loss.

According to ethical approaches such as duty ethics and virtue ethics, calculation of harms and benefits alone cannot be the basis for justification of an action, as it excludes other relevant aspects. Within an animal rights version of duty ethics, the animal is seen as an individual worthy of respect in its own right, and should not be regarded as a mere instrument for human purposes (Regan, 1983; Francione, 2010). This view excludes both breeding and housing of farm animals for production and is thus difficult to embrace for animal scientists. However, it may still add a relevant perspective for ethical elaboration because this view is embraced by some members of the society. The animal integrity concept reflects a sense of respect for the animal as a sentient being experiencing its own life and existing on its own premises before we define it through its function for human purposes (Röcklinsberg et al., 2014). Rutgers and Heeger (1999) defined animal integrity as the "wholeness and intactness of the animal and its species-specific balance, as well as the capacity to sustain itself in an environment suitable to the species." This view is an influential branch of animal ethics, pointing at aspects beyond animal welfare, concerning the overall respect for another being. Hence, it advocates limits set for acceptable treatment of animals other than utilitarian calculations. Where these limits are set cannot be answered by scientific facts; rather, each answer is embedded in a person's set of values, choice of ethical theory, and worldview.
For example, embryo transfer (and by implication, cloning) is not approved within organic farming in the EU (European Union, 1999). This is not because of concern for welfare impairment of the dam but because it touches upon what is perceived unacceptable interference with the nature of animals (Nauta et al., 2005; Lund, 2006). It seems fair to conclude that, independently of what one regards to be the right course of action, both welfare-related arguments and other factors are ethically relevant to consider when it comes to an assessment of reproduction technology.

\section{Improved Biotechnological Methods to Change the Genome}

The first genetic modifications of farm animals were generated in the mid-1980s (Hammer et al., 1985) and methods have improved considerably since then. Different techniques have been used to create transgenic animals, such as direct microinjections, or microinjections of transposons into pronuclei or embryos, the use of lentiviral vectors, sperm-mediated transfer of DNA, and DNA transfer via cloning (Houdebine, 2009; Miao, 2013). Early methods to generate GM livestock animals such as pronuclear microinjections had low efficiency, with uncertain results and a low frequency of live offspring with the targeted genetic modifications. To produce a single transgenic calf, approximately 1,600 eggs were microinjected. About 15\% of transferred embryos survived to term, and the transgene was expressed in only half of the transgenic offspring born (Wall et al., 1997). The use of SCNT has the advantage that modified somatic cells that have the desired genetic change can be selected as donors for cloning. All liveborn calves will then carry the genetic modification (Wang, 2015).

Efforts are continuously made to improve techniques and, recently, so-called molecular scissors have further improved the efficiency. Engineered nucleases in the form of zinc finger nucleases (ZFN), transcription-activatorlike endonucleases (TALENS), or clustered regularly interspaced short palindromic repeats with associated protein 9 (CRISPR/Cas9) enable targeting and cutting the DNA strands at desired locations. Endogenous cell repair mechanisms (homology-directed repair or nonhomologous end-joining) then introduce new genomic variants, and it is possible to select for targeted gene knockouts or insertions (Petersen and Niemann, 2015). With these designer nucleases, precise and efficient changes can be made in farm animal genomes without integration of foreign DNA. It is possible to restrict the DNA strand repair to the homology-directed pathway to avoid unwanted off-target cleaving events (Petersen and Niemann, 2015). Wei et al. (2015) showed that it is 
possible to generate bovine embryos that are homozygous for a precisely edited allele.

In the generation of genome edited farm animals, SCNT has continued to play an important role, but microinjection in embryos (zygotes) is now an alternative method to generate GM or genome edited large animals (Petersen and Niemann, 2015; Wei et al., 2015). Problems with SCNT related to reprogramming of the somatic cell nucleus in the recipient cell can then be avoided, implying a reduced negative effect on animal welfare. In the review by Tan et al. (2016) on genome edited cattle, sheep, and goats, efficiency in terms of number of edited per live born was lower for cytoplasmic injection of zygotes than for SCNT (8.2 vs. 81\%), whereas cytoplasmic injections gave a 2-fold-higher pregnancy rate and a greater number of liveborn per pregnancy than SCNT (1.2 vs. 0.2).

\section{Ethical Aspects of Different Biotechnological Methods to Change Cattle Genomes}

In this section, we will highlight some ethical considerations regarding the use of classical GM and genome editing as such. Considering the methods from an ethical perspective, it may be relevant to distinguish between different kinds of genetic changes. Ranged along a spectrum of changes, we can see 3 levels: (1) genome editing, where a few nucleotides are changed to variants already existing within the species (and then traditional breeding methods may be implemented); (2) making more extensive changes within a species, such as using vectors to transfer genetic code; and (3) introducing active genetic material from another species. Effects of genome editing and intra-species modification can be seen, to some extent, as human-imposed mutations, whereas targeted genetic change introducing DNA from another species would not have occurred in nature. Whether or not the degree of interference is an ethically relevant aspect is a question of fundamental ethical principles or perhaps even view of life perspective. Although open to definition (van Haperen et al., 2012; Siipi, 2013, 2015; Sandin, 2017) and difficult to implement in action, "naturalness" frequently occurs in both the societal and the philosophical discourse. Siipi (2015) argues that not all definitions of naturalness are ethically relevant, but also that even if one regards GM food to be natural in one sense (e.g., humans are part of nature and hence all our actions are natural), this does not per se exclude other definitions of natural from being ethically relevant. Such definitions could be "independence from human beings," "nutritional suitability," or "environment friendly" (Siipi, 2015). Further, it has been shown that naturalness is an often-used formulation of a moral limit to human food choices or actions in general (Rozin et al., 2004; Tenbült et al., 2005; Lassen and Jamison, 2006). Based on the view that naturalness is a relevant concept for many citizens, one can argue that, for instance, polled cows are more natural and thereby more acceptable than transgenic cows producing human protein variants in their milk. We have chosen to discuss these 2 cases further later in this review.

Further, risk assessment needs consideration and, here especially, genetic changes that will remain for generations are ethically relevant. For instance, if the genetic modification leaves traces of DNA from other species or GM animals are spread by mistake (e.g., GM fish escaping from sea cages) or on purpose (e.g., modified insects spread to combat diseases), there will be different views on how to handle risks and unforeseen consequences, as well as whether there is a need to take action (Sandin, 2004; Myhr, 2010). Precaution includes both risk detection and risk management. For example, within the organic movement, precaution is considered a suitable principle for risk perception when it comes to new techniques such as GM (Padel et al., 2009; Wickson et al., 2016). The precautionary principle is thought to be important, especially in research having dual use, such as techniques developed for a benevolent purpose but that could be used for other aims, exemplified by nuclear energy (Kuhlau et al., 2011). Context awareness, reflection, and considerate decision-making are core concepts that may, according to Kuhlau et al. (2011), be successfully combined with the precautionary principle for risk management. With reference to genetic changes in animals, one could argue that researchers need to be aware of their own role and responsibility in seeking information on potential causes of harm in a wider context than their specific genetic research question or related to the welfare of the animals strived for. Inclusion of such wider aspects could imply acknowledging limits of our current understanding of the new technologies regarding, for example, genetic control of complex traits, identification of functional mutations, and mapping of pleotropic effects. Application of the precautionary principle in the $\mathrm{EU}$ is limited to risk management in political decisions and has been widely understood as a decision rule that hinders balanced decision-making. It is generally more difficult to prove that something is safe than to find potential risks, which may lead to prohibiting scientific development and practical applications of new techniques. In some cases, the damage done by denying the application might exceed the potential risks associated with a new technique (Hathcock, 2000). A balanced use of the precautionary principle has been advocated 
(Tait, 2001), and according to Weimer (2010), it should be seen rather as a procedural principle facilitating thorough reflection.

\section{Breeding Schemes Incorporating GM or Genome Edited Cattle}

The use of new technology to make precise genetic changes has been advocated as a potentially efficient and rapid tool to improve important traits in livestock (Laible et al., 2015). It would indeed be advantageous if generations of selection within breed or backcrossing to regain genetic level after introgression of specific genes from inferior breeds could be avoided. Even without GM or genome editing, the rapidly adopted use of genomic selection based on genome-wide marker panels with SNP as a breeding tool has opened up new possibilities for earlier selection of animals and reduction of progeny testing (Jonas and de Koning, 2015). However, the use of genomic selection can only improve a population when genetic variation for the trait can be found within the breed.

Genetically modified and genome edited farm animals have, until now, been generated only within restricted environments, targeting either production of pharmaceuticals or improvements of livestock within research projects. To our knowledge, there are no longterm, large-scale breeding programs incorporating GM or genome edited farm animals for food production. For such a program to be possible, legal approval is necessary but has, so far, not been given, which has prohibited practical applications in livestock for food production. Early GM pig breeding programs, such as the EnviroPig, failed largely due to complex regulatory frameworks (Sanderson, 2015). The only GM animal with approval for human consumption is the AquAdvantage salmon (FDA, 2015). AquAdvantage salmon are fast-growing triploid, sterile females produced from non-GM Atlantic salmon dams and GM sires (AquaBounty Technologies, 2013). The publications regarding this GM fish do not reveal whether the GM males are also selected for other traits in a breeding program. Large-scale cattle breeding programs are complex, and continuous selection would be required even if GM or genome editing could improve one or a few main traits of interest.

The use of GM in farm animals may seem unlikely to some, but advanced high-technology methods are already accepted and in use. Advanced ART combined with genomic selection is incorporated in many dairy cattle breeding programs. Studies performed today deal with the possibility of shortening the generation interval further and thus increasing the genetic gain. Genomic selection of preimplantation embryos could give extremely short generation intervals (Kadarmideen et al., 2015; Kasinathan et al., 2015). Together with the use of sexed semen or embryo sexing and SCNT, efficiency in the breeding program may increase even further. Possibilities for collection of increased amounts of DNA (e.g., for whole-genome sequencing and storage) from early embryo biopsy were suggested by Kasinathan et al. (2015). The breeding activities would include transferring multiple embryos from elite donor cows to recipients, collecting embryos from the recipients after $3 \mathrm{wk}$, and using them to establish fibroblast cell lines. Genetic material from these cell lines would then be genotyped and the best ones selected and used as SCNT donor cells. The resulting embryos would be transferred to non-elite recipient females and result in high-merit live calves. It is not difficult to imagine the integration of genome editing to further improve embryos in a similar program (Figure 1). Genome editing could be used to modify either zygotes or somatic cells (fibroblasts) in such a system.

How would a future breeding program with applications of GM or genome editing in livestock be designed? Jenko et al. (2015) simulated and compared different scenarios where genome editing was used to improve a quantitative trait in a livestock breeding program. They concluded that genomic selection together with promotion of alleles by genome editing gave a higher selection response than the use of genomic selection alone. Their simulation was based on several assumptions that (as the authors pointed out) are currently more or less unrealistic, such as faultless knowledge of (all-additive) quantitative trait nucleotides (QTN) and effects, perfect accuracy of genomic selection, and errorfree genome editing (Jenko et al., 2015). The ability to make multiple genome edits at the same time would make the technique more useful for quantitative traits. This is anticipated to become a reality within a few years (Jenko et al., 2015) and studies in model species are ongoing (Sakurai et al., 2016; Zerbini et al., 2017).

Modern breeding goals for cattle are typically broad in the sense that they incorporate various functional traits in addition to production traits. Unfavorable genetic correlations between production and fertility or health traits are commonly found and need to be considered in the breeding program (Rauw et al., 1998). Different steps are taken, therefore, to select the best breeding stock and to monitor genetic gain in different traits to control unwanted effects (Figure 2 ). Favorable QTN alleles can be promoted with the use of genome editing in the population independently of other QTN in the population (Jenko et al., 2015). This may be an advantageous asset especially if traits are unfavorably correlated because of linkage disequilibrium. Nevertheless, the genetic background of many 
quantitative traits, and their genetic interactions, is more complex as effects can be specific to environment or sex, and epistatic effects may exist (Mackay, 2004). This complexity is important for conventional breeding, and it can make the outcome of genome editing of multiple QTN for complex traits difficult to predict with certainty. The application of GM or genome editing would seem more straightforward in the case of monogenic traits with known allele sequences. Among others, Hickey et al. (2016) proposed the use of genome editing to fix favorable alleles for traits related to, for example, disease resistance, polledness, or myostatin. To use genome editing to remove known harmful recessive alleles that impair fertility or health and in that sense repair accumulated damage in the genome of breeding animals was pointed out as one of the most obvious potential applications of genome editing in farm animals by Simianer (2016). However, even in the case of monogenic traits, the total effect of genome editing on the animal needs to be considered. As an example, a deletion in the bovine myostatin gene (MSTN) affects the regulation of skeletal muscle growth, causing the double-muscled phenotype common, for example, in the Belgian Blue cattle breed (Grobet et al., 1997). Attempts have been made to use genome editing to modify this gene in other cattle breeds but using other mutations than the one initially identified in Belgian Blue cattle (Proudfoot et al., 2015). The aim is to

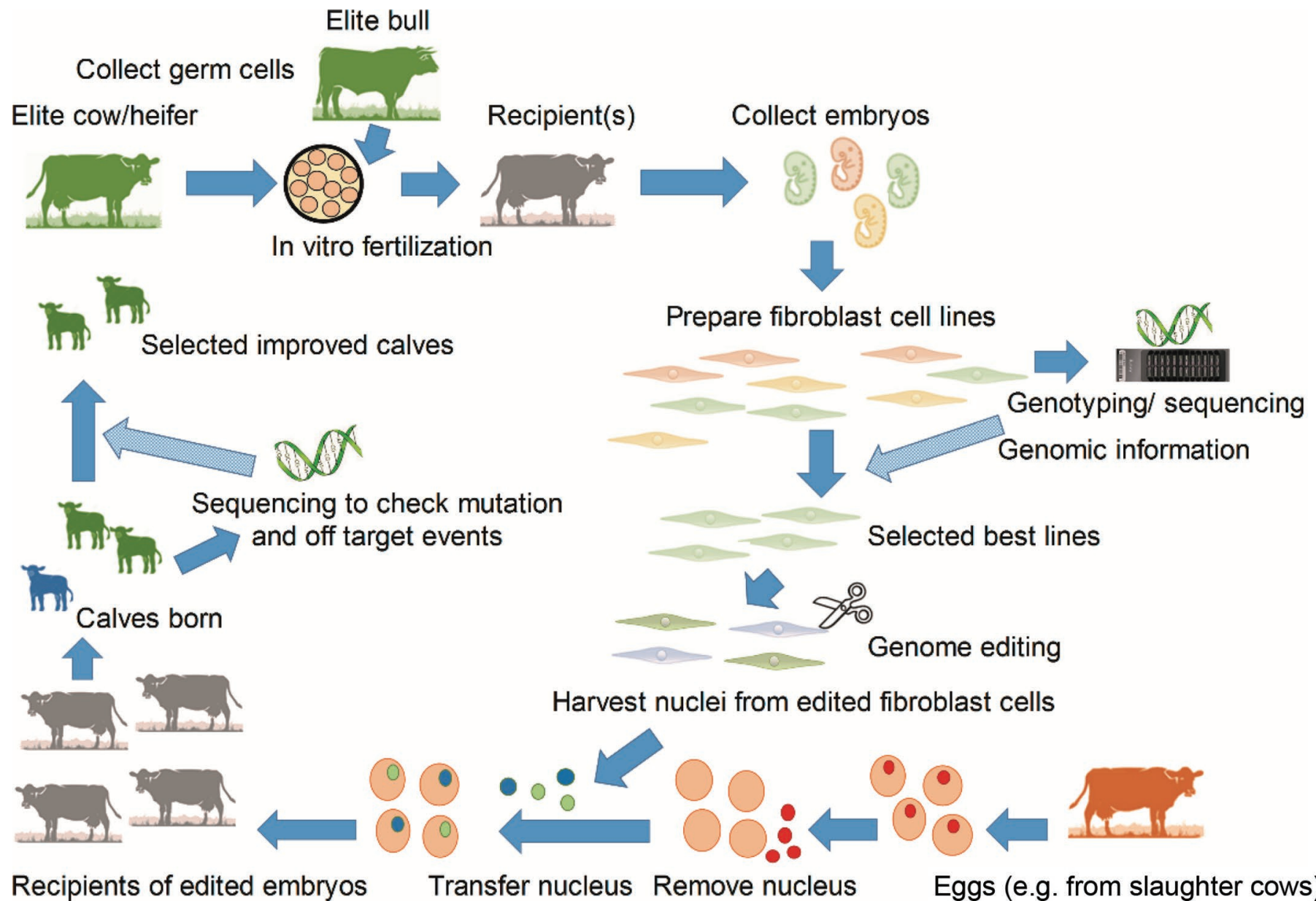

Figure 1. Illustration of possible inclusion of genome editing in a cattle breeding program with genomic selection of embryos. Germ cells collected from elite cows and bulls with high genetic merit are used for in vitro fertilization. The embryos are transferred into recipient females (multiple embryos per female possible), and, after some time of development, collected and used to prepare multiple fibroblast cells lines from each original embryo. One part of each cell line is used for genetic testing and the other will be used further if selected based on genomic breeding values. The selected fibroblast cells may be genome edited to introduce further genetic modifications of interest. Nuclei from selected fibroblast cells are transferred into egg cells from which the original nuclei have been removed, whereupon these are developed until blastocyst stage and then transferred to recipient cows. Recipient cows can differ between the different stages as hormonal treatments are needed for synchronization of the cycles. The liveborn calves are genotyped to identify successfully edited individuals carrying the introduced mutation that will be used as the next generation of breeding animals. Green animals in the figure indicate the superior selection candidates. 
Environment:

production system; infrastructure; market

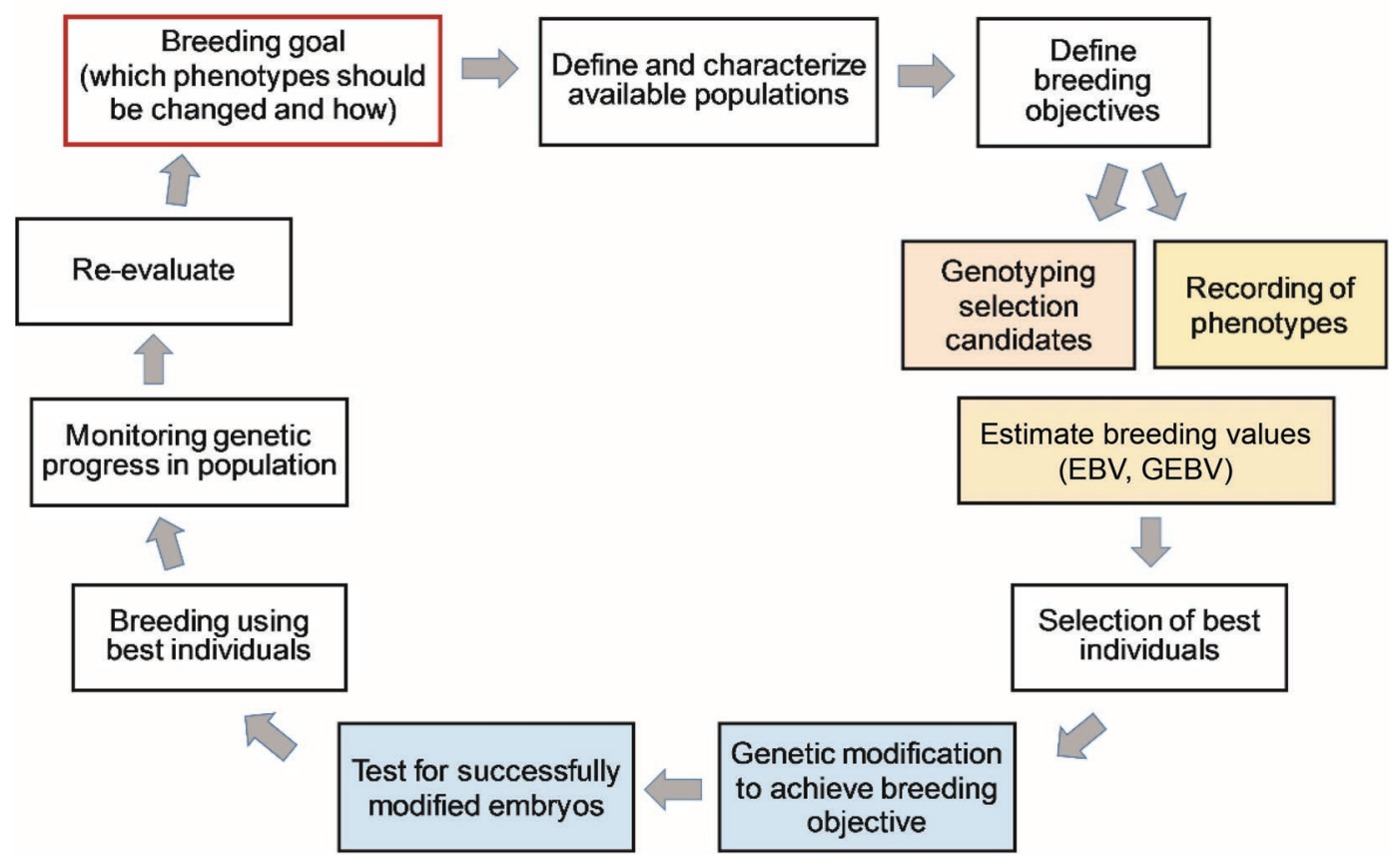

Figure 2. Schematic breeding program including genetic modification. GEBV = genomic EBV. Color version available online.

achieve more-efficient meat production with higher meat yield and a larger proportion of high-value retail cuts. The double-muscling syndrome in cattle has been associated with problems such as dystocia, reduced calf survival, and reduced fertility, as reviewed by Arthur (1995) and Fiems (2012). The phenotypic effects can differ depending on the modification made in MSTN, but effects of changes in this gene on such functional traits need to be monitored and evaluated.

An important aspect of breeding programs including a limited number of highly valuable breeding animals (e.g., GM or genome edited elite animals) is the risk of an increased inbreeding rate and thus inbreedingrelated problems in the population (Blasco, 2008). In their simulation study, Jenko et al. (2015) pointed out that inbreeding needs to be managed if the number of edited sires is limited. This is highly relevant because intensive selection within the internationally widespread Holstein breed has already led to limited effective population size (Mc Parland et al., 2007; de Roos et al., 2008). The international exchange of elite dairy bull semen implies that modifications of highmerit animals within one breeding organization could rapidly be introduced in populations in other countries. Considering cost efficiency, few (international) topmerit animals may initially be selected as donors of cells to create GM or genome edited clonal cell populations via SCNT. The resulting animals would then be groups of identical clones from this limited number of donors. With direct microinjections of zygotes, any desired combination of parents can be used and thus the progeny can be more genetically diverse. However, the risks of off-target changes or mosaicism when using microinjection need to be further reduced (Tan et al., 2016). If microinjections of zygotes become more precise, this will enable production of edited embryos on a larger scale in livestock. It is possible that a large proportion of AI bull candidates, if not all, may be edited in the future; in such a scenario, genome editing would not increase the inbreeding rate further.

Livestock breeding programs undergo changes, often based on new technologies. Recently, the use of genomic selection has led to changes in the selection process, especially in Holstein cattle populations. Adjustments of breeding programs would likewise be expected if GM or genome editing were incorporated. The breeding goal and selection strategies may be changed if new traits can be included as a consequence of novel genetic variants. Furthermore, changes of the registration of individual identity may be needed to allow identification of GM individuals and their offspring (Forabosco et al., 2013). The need for such additional registration would 
depend on the future legalization, as well as on demands from breeders, producers, and citizens. Cost efficiency and success rate of the reproduction and biotechnological methods will be relevant factors to determine the applicability of new technologies. The potential risk of off-target modifications or unwanted side effects due to complex genetic interrelationships, in relation to the increased gain achieved, will affect the attractiveness of incorporating GM or genome editing in breeding programs. The steps in a breeding program that would potentially be altered are indicated in Figure 2 .

\section{Ethical and Practical Aspects of Adjusting Breeding Schemes to GM or Genome Editing}

In an overview of important technologies implemented in animal breeding, Simianer (2016) discussed why only some of the inventions have had a large effect on breeding programs. He argued that to become quickly adopted and implemented, novel technologies must not only be suitable for daily use, benefit the breeding program, and be cost efficient, but they also have to be accepted by society. However, it is an open question when or if general societal acceptance of food items produced by GM will be achieved. The general view in Europe is exhibited in restrictive legislation, which affects what breeding organizations may and may not do and need to consider in case of future changes.

Besides ethical issues about reproduction techniques and modification of the cattle embryo discussed in the sections above, several ethical aspects relate to inclusion of GM or genome editing into breeding programs, two of which will be discussed here. One is related to the ambition to avoid and handle unwanted effects by monitoring changes in different traits. With precise modifications applied on a limited number of genes, it is possible to create "pilot" individuals in a process aiming to eliminate unwanted traits or repairing genome damage in a breeding stock. This makes it possible to follow the development of each first-generation individual. If we regard GM or genome editing as such acceptable, this is advantageous. Even though there is a difference in complexity between monogenic and polygenic traits, unexpected effects may appear even with apparently simple modifications. Our knowledge of genetic mechanisms (e.g., regarding epigenetic phenomenon such as genomic imprinting) is still far from complete.

It is understandable that improving disease resistance or establishing a polled breeding line-for example, through GM or genome editing-would be attractive. From an animal welfare perspective, there are reasons to be positive provided that legal welfare requirements are met throughout the process. Negative effects on animal welfare, such as certain changes in the $M S T N$ gene might bring, would from an animal welfare perspective need to be considered in a cost-benefit analysis. Regarding editing of multiple QTN, the genetic complexity and possible interlinkage between loci require reflection in each step of the process. As in any conventional breeding program, the breeding organization would need to consider the multifaceted interrelations between traits and take responsibility to avoid unwanted side effects on animal welfare and health from introduction of GM or genome editing in the breeding scheme. To be able to identify GM individuals may be important to fulfill expectations of consumers, producers, and authorities for high standards in safety and traceability (Forabosco et al., 2013). Also from ethical points of view, wellfunctioning tracing and recording schemes of both positive and negative effects constitute a necessary factual basis for ethical decisions by breeding organizations, consumers, and authorities on where to go next.

A second ethical issue concerns the practical side of increasing efficiency in establishing changes in subsequent generations by using elite donors and embryo selection, in a breeding program similar to that suggested by Kasinathan et al. (2015) to decrease the generation interval. The procedures described by Kasinathan et al. (2015) primarily aimed to decrease the generation interval, without a focus on GM or genome editing. Ethical concerns about the handling of females or embryos are thus equally relevant for all breeding programs using these methods. Provided that the number of very high ranked females used as donors was relatively low, the impression may be that few individuals would be used in reproduction and modification procedures. A closer look reveals, however, that the elite individuals used to produce the genetically modified clonal cell population via SCNT might be used more extensively, and that a large number of recipient females and intrusions in embryo development are needed. Intuitively, this can be considered at odds with respect for life or for the process of creating a unique individual, and it is questionable from any ethical point of view ascribing animal embryos an ethical standing, for example, by holding individual integrity.

In general, discussions about animal integrity concern individuals after birth, but the technologies in focus here show that it might be relevant to ask at what age species-specific capacities and functions are developed, and whether the individual needs to perform them outside the uterus to found its individual integrity. The view that animals have integrity that can be harmed may be related to a more general ethical notion of respect for the "zone of untouchableness" of an individual being (Röcklinsberg et al., 2014). As a con- 
sequence of the gene technology debate, the concept of "Würde der Kreatur" (the dignity of the creature) was included after a public vote in the Swiss Bundesverfassung (national legislation) 1992 and ever since widely debated both in bioethics and from a philosophy of law perspective (Baranzke, 2002; Rippe, 2011). It called for respect for the welfare and dignity or integrity of the animal, which imposed moral obligations on humans. Hence, genetic modifications might impair both and the legislation aimed at ensuring it would not. This stricter perspective on the researcher's role - considering ethical aspects beyond welfare - is also in the guidelines Ethical Principles and Guidelines for Experiments on Animals (EPGE) by the Swiss Academy of Medical Sciences and the Swiss Academy of Sciences (2005). Since 1983, The EPGE is declared binding as a code of conduct for all researchers and their scientific collaborators working in Switzerland. For example, researchers are expected to balance a fundamental ethical realization of "respect for life" with probable benefits from research. Holding this perspective, each step of collecting eggs, editing genes, creating cell lines, and transferring embryos is considered ethically relevant and in need of justification. This view may seem foreign to many animal breeders but, as illustrated above, it has both philosophical and regulative foundation and may have an effect on or mirror public concerns and decisions about regulations of GM and genome editing.

Some further ethically relevant issues connected to the use of GM and genome editing in breeding schemes are worth mentioning here. One is related to counteracting increased inbreeding rate. A lack of diversity in breeding populations can imply a risk of future costs in terms of lost opportunities to select for certain capacities, impaired fitness traits, or decreased adaptability to new environments or demands, and has therefore been highlighted by the Food and Agriculture Organization of the United Nations (FAO, 2007). There may be advantageous effects of genome editing on genetic diversity if it can increase, for example, the number of breeding animals with different genetic backgrounds carrying a genetic variant selected for. On the other hand, if it leads to more intensive use of modified elite animals, it could contribute to an increased inbreeding rate. Another issue deals with the mere scale of the applications. There is an enormous difference in magnitude between experimental use of genome editing in a laboratory and extensive use of edited breeding animals in large-scale breeding programs worldwide. The changes are designed to remain in generations to come, and our ability to ensure that lines of animals are not edited or that the process could be reversed in the future may be small.

\section{CASES}

\section{Case 1: Genome Editing to Eliminate Dehorning}

Genetic dehorning of cattle is a likely candidate for the application of genome editing of farm animals on a large scale. Polledness (the genetic absence of horns) is an autosomal dominant trait and there are likely 2 independent mutations that have occurred and been selected for in different cattle breeds (Medugorac et al., 2012). In modern dairy and beef farms, dehorning is commonly used to prevent injuries to animals and humans, especially in loose housing systems. Here, we use the term "dehorning" both for amputation of more or less outgrown horns and for disbudding in young calves. Today, more than $80 \%$ of European dairy cattle are dehorned, in most cases without pain relief medication (Cozzi et al., 2015). Dehorning is a costly and time-consuming process. Furthermore, dehorning without anesthesia has been shown to cause measurable responses associated with pain in cattle (Stock et al., 2013), and is thus a clear animal welfare issue. We here exclude the potential ethical discussion on whether or not losing horns could be seen as harmful for cattle in other ways, such as affecting animal integrity.

Genetically polled breeding bulls are available in many cattle populations. However, in the most numerous dairy breed-Holstein - the number of genetically polled AI breeding bulls is still low, and only a few polled Holstein bulls are homozygous for the polled allele. The demand for genetically polled cattle and thereby the number of polled Holstein AI bulls has increased, but Windig et al. (2015) found that genetic merit was still lower for polled bulls and they were more inbred than horned bulls. Spurlock et al. (2014) concluded that intensified use of polled bulls would reduce the genetic level in Holsteins, whereas the effect would be less in the Jersey breed. When selecting for polledness, it is necessary to control relatedness and inbreeding and to use special elite mating schemes to avoid loss of genetic gain (Windig et al., 2015).

Genome editing has been proposed as a short cut to produce top-merit polled bulls while avoiding both losses in genetic gain and the use of closely related polled individuals. The use of genome editing would allow production of a large proportion of animals that are homozygous for the favorable allele (Laible et al., 2015), and a larger number of homozygous bulls would increase the allele frequency in the population. Selective matings of horned, homozygous, and heterozygous polled breeding bulls and cows could be used to optimize the number of polled calves born (Spurlock et al., 2014). A precise and small change in the genome 
that mimics what already exists within the species, or breed, may be considered a minor interference. When no foreign DNA is incorporated, it may not even require permits for genetic modification, but the regulation for genome editing is not final in either crops or animals (Carroll et al., 2016; Wolt et al., 2016).

The first reported cases of genome edited polled calves were produced using SCNT (Carlson et al., 2016). Using SCNT, a selection of embryos with the targeted modification could be made before embryo transfer into a recipient cow. An alternative method could be microinjection of editing reagents in zygotes (Tan et al., 2016). To successfully utilize genome editing to increase the frequency of polled cattle, sires and dams of modified embryos would have to have high genetic merit, and if the number of animals to be edited is limited, they should also be as unrelated as possible. The selected modified embryos must be numerous enough to spread the polled allele faster in the population compared with the use of naturally polled AI bulls, without increasing the inbreeding rate further. In a scenario where genome edited cattle enter large-scale breeding programs, a combination of naturally polled, genome edited polled, and (de)horned breeding animals would be used. Because of allelic heterogeneity in the POLLED locus, the naturally polled and the genome edited polled animals may carry different alleles. In the first genome edited polled Holsteins (Carlson et al., 2016), the genetic code for polledness used for editing was the one of Celtic origin (common in the Angus beef breed, for example), which is different from the more complex allele of Friesian origin typically found in polled Holsteins (Medugorac et al., 2012).

\section{Case 2: Insertion of Human Genes to Increase Udder Health in Dairy Cattle}

Udder health is of great economic importance in dairy production, and contributes to animal welfare. Cows with mastitis have been reported to show behavioral and physiologic responses associated with pain (Leslie and Petersson-Wolfe, 2012). Poor udder health is one of the most common reasons for culling in modern dairy herds (Ahlman et al., 2011). There are thus strong incentives to rapidly improve udder health using available tools, including GM.

Clinical mastitis has long been recorded and included in the breeding goals for dairy cattle in the Nordic countries. Estimated heritability values have generally been low, but favorable genetic trends have been shown (Heringstad et al., 2000; Philipsson and Lindhe, 2003). Not all countries have well-developed recording of clinical mastitis, however, and indicator traits such as milk SCC are commonly used in breeding programs to improve udder health. These are easier to measure on a continuous scale in a standardized way, resulting in a somewhat higher heritability than for clinical mastitis. Still, indicator traits are less informative than the goal trait (Heringstad et al., 2000). Even though other indicator traits of clinical or subclinical mastitis, such as milk conductivity (Norberg, 2005), can be automatically recorded and used as an additional information source, unfavorable genetic correlations with milk production traits slow the genetic progress in udder health traits.

Several candidate genes for mastitis resistance or susceptibility are presented in a review by ThompsonCrispi et al. (2014). For example, polymorphisms exist for the bovine lactoferrin- and lysozyme-encoding genes (Seyfert et al., 1996). A heritability of 0.22 was estimated for lactoferrin content in bovine milk (Arnould et al., 2009), indicating that genetic selection for increased lactoferrin content is possible. The complexity of the mastitis resistance trait remains to be a challenge, however, and adequate bovine mastitis control is still lacking in spite of breeding and management practices (Thompson-Crispi et al., 2014).

Modification of the production of milk proteins was identified early as a useful agricultural application of genetic engineering (Cooper et al., 2015). One of the potential targets is the glycoprotein lactoferrin that plays an important role in the innate, nonspecific host defense against pathogens. It is present in bovine colostrum and, albeit at lower concentration, in milk and other secretory fluids (Pakkanen and Aalto, 1997). The content of lactoferrin in bovine milk is considerably lower than that in human milk (Rainard and Riollet, 2006). Similarly, the protein lysozyme, which is present at very low concentrations in bovine milk but at higher concentrations in human milk, can help in the defense against several pathogens (Rainard and Riollet, 2006). The peptide human $\beta$-defensin-3 (HBD3), with a broad-spectrum antimicrobial function, is present in different human tissues but not normally in bovine milk (Dhople et al., 2006; Chen et al., 2016). Genetically modified cattle that produce recombinant human lactoferrin, lysozyme, or HBD-3 in milk have already been generated (Cooper et al., 2015; Chen et al., 2016). Simojoki et al. (2010) showed that transgenic cows that produced recombinant human lactoferrin in the milk did become infected by Staphylococcus chromogenes but showed fewer symptoms and eliminated the bacteria faster than nontransgenic control cows. In other studies, GM cows expressing HBD3 (Chen et al., 2016) or human lysozyme in milk (Liu et al., 2014) seemed to be more resistant to bacterial udder infections than nontransgenic controls. In addition to improved udder health in the dairy cow, production of bioactive recom- 
binant human lactoferrin, lysozyme, and potentially other agents in the milk could improve gut health of human consumers. The review by Cooper et al. (2015) presents beneficial effects on intestinal health and microbial flora and improved growth, iron status, and recovery from infections in pigs, rats, and mice fed with milk from transgenic cows expressing human recombinant lactoferrin or lysozyme.

\section{Discussion: Context Sensitivity from a Holistic Perspective}

Genome editing has sometimes been presented as a "quick fix" to rapidly introduce a new trait, such as polledness or production of certain milk protein variants, in a population. Any animal welfare issues directly related to the process of GM or genome editing would then be relevant for only one or possibly a few generations. It may be argued that the welfare benefits to multiple future generations could outweigh potential suffering of a limited number of animals. It should be kept in mind though that animal breeding is targeting a continuous accumulation of genetic improvements, leading to genetic gain. If one application of GM or genome editing is successful; for example, introduction of genetic polledness in a breed, it is more than likely that the breeding company would continue with further modifications to improve or introduce new traits.

Once a method in a certain field is approved and established, it is often expected that it will be used. However, in the case of GM, the situation has been different, with extensive regulatory barriers, and introduction and application has not followed directly from what researchers regard to be an established technology. This may be due partly to the relatively higher complexity in large-scale application of genetic modifications of food-producing animals, with several levels of ethical dimensions to be considered. Different viewpoints and value clashes among parts of the society have led to long-lasting discussions about GM (Fischer and Eriksson, 2016), with different aspects in focus depending on region (Frewer et al., 2013b). The debate on GM has been more intensive than for new applications of, for example, ART. From an ethical point of view, introduction of methods should be scrutinized from several perspectives. It is important to consider both costs and benefits, regarding the possible gain and probability of reaching the aim, possible positive and negative consequences for animals used in the development process and for those with an edited genome, as well as aspects of animal integrity and the perception of producers and the public. Improvements of the technologies over time could lessen animal welfare concerns, but so far, the problems with negative side effects of in vitro handling of embryos have proven difficult to solve. Increasingly advanced ART are already in use in cattle breeding today, however, and their use may increase further for reasons other than to enable GM or genome editing.

With rapid technological development, it is clear that the alternative to refrain from using any form of GM or genome editing is also an active choice that requires ethical considerations. The increase in world population creates challenges and demands that are often suggested to require further technological advances in several areas related to food production (Tian et al., 2016). The use of GM and genome editing could contribute to reducing the environmental impact of animal production, for example, by decreasing amounts of manure phosphorus, as has been described for pigs (Golovan et al., 2001). More general genetic progress in dairy cattle can also be expected to increase production efficiency and lower greenhouse gas emissions per kilogram of milk solids (Pryce and Bell, 2017), either achieved by traditional breeding or enhanced by genome editing. Several studies have suggested that animals' resistance to different diseases could be increased by the use of GM or genome editing (Liu et al., 2014; Burkard et al., 2017; Gao et al., 2017), potentially reducing the need for antibiotic treatment of diseases or secondary infections. Very expensive and time-consuming assessments and complicated regulation processes that prevent the adoption of new technologies thus also limit our options to handle future challenges through such means.

In the cases discussed above, the choice to not use genome editing to make cattle genetically polled implies that dehorning would continue on a large scale for a longer period. With increasing numbers and improved genetic merit of naturally polled bulls, the advantages of genome editing must be obvious to motivate the use of this technique. The effect on animal welfare of refraining from using GM to create animals that produce certain milk proteins to improve udder health is less clear, because this trait is much more complex and strongly influenced by environmental factors. It could be argued that benefits of GM or genome editing for animal welfare are only relevant if animal management is not downgraded as a consequence; for example, if more resistant animals are kept in less hygienic stables or polled animals are kept in more crowded enclosures. However, cattle breeding programs are already aiming for genetic improvements of health, function, and production, and it requires a deeper analysis to evaluate whether it would be justified to discriminate between methods to achieve these goals because of concerns for effects on management.

The nature of the 2 cases discussed above differ in the sense that genome editing does not leave any foreign genetic code and that the genetic variant for 
polledness is already present within the species (but not necessarily within the breed), whereas the modifications for improving udder health create transgenic animals containing a fragment of human genetic code. Consumers and citizens can be assumed to more easily accept GM or genome editing that benefits animal welfare (Frewer et al., 2013a). For reasons given above, genetic dehorning of cattle may be one of the least controversial applications. However, it brings additional costs in terms of money and discarded embryos, potential risks of off-target events and animal suffering, and possibly negative consumer reactions. Potential additional benefits of human protein variants in bovine milk for consumer health bring an additional aspect of GM cattle. If the greater public acceptance for GM animals as bioreactors compared with GM to increase food production (Mora et al., 2012) would apply on a larger scale, then transgenic cattle producing milk with substantial health benefits (e.g., for young children) may be more easily accepted.

According to Lassen and Jamison (2006), the public "cultural discourse" criticism of gene technology is partly based in perception of it harming the order of nature. Two further argument clusters for criticism found in their focus group study are the "societal discourse" (e.g., health and environmental aspects) and the "economic discourse" (e.g., fair business). Lassen and Jamison (2006) argue that these aspects are not sufficiently considered by policy makers and politicians. A recent study of how key actors in the Swedish food chain perceive biotechnology in relation to sustainable agriculture shows an ambiguous view. Even though key actors may be neutral or positive themselves, they may be reluctant to introduce a product on the marked due to expected consumer skepticism related to health aspects, criticism of the "playing God" attitude, and issues of business fairness (the role of large companies; Björnberg et al., 2015). Hence, recent studies support the need for a nuanced discussion of aspects other than mere biological facts about genetic changes or welfare assessments of modified animals.

\section{CONCLUDING REMARKS}

With this article, we wanted to merge approaches of genetics and ethics to achieve a comprehensive discussion on the hot topic of genetic modification and genome editing. Emerging new technologies such as genome editing have the potential to be of great importance in the future and to benefit both animals and humans. To refrain from using new genetic technologies to increase food production or lessen the environmental or climate impact from cattle could be considered irresponsible, as pointed out by Laible et al. (2015). In the short term, however, we find that genome editing especially is often presented in the media as a rapid and uncomplicated way of solving complex problems, whereas our present knowledge about the genetic background of important traits is incomplete and the difficulties in large-scale application may be underestimated. Perhaps "Amara's law" by American researcher and futurist Roy Amara applies in this case: "We tend to overestimate the effect of a technology in the short run and underestimate the effect in the long run."

The concept of genome editing has already been presented to the public by the media. It is important that clear and honest information about different methods and their potential use and consequences be provided by researchers. A willingness to discuss ethical dimensions with stakeholders and an awareness of possible controversies may decrease the risk of miscommunication. We find that questions regarding GM and genome editing should be discussed within a relevant contextin this case, modern farm animal breeding - and not as a separate phenomenon. A similar view was expressed by the Nuffield Council on Bioethics (2016) regarding genome editing. We see a need to include all steps of the process in an ethical consideration when introducing new technological methods in breeding of farm animals (e.g., the ART used). This should not be dismissed as unimportant because several steps in the process could evoke reactions from consumers and citizens. We acknowledge that it is difficult to predict reactions among the public (Björnberg et al., 2015) and challenging to create arenas for discussion and to handle tensions between scientific risk characterization and broader risk management governance incorporating, for example, ethics and politics (Hartley and Millar, 2014).

Because the limiting factor is not what is technically possible to do but rather what is reasonable to do, we need increased awareness about the basis for and arguments behind "go/no go" decisions (Bruce, 2016a). Animal breeding organizations and companies have both a responsibility and an advantage in evaluating the benefits, costs, and further ethical aspects of the methods within a relevant context. To leave the ethical discussions and decisions about GM or genome editing primarily to parts of society with less insight in genetics and animal breeding procedures would be suboptimal. There seems to be a need for ethical advisory boards, or committees, in breeding organizations to avoid the risk that several smaller changes, that are not necessarily challenging individually, together lead to a "slippery slope." Such advisory boards would ideally act as a resource for breeding organizations in internal discussions and decision-making rather than creating additional regulations or external control. The implementation needs to be made with care, taking each organization's 
topical ethical issues as point of departure to ensure that it is not imposed from outside. Such boards are already in place in some countries. For example, the Dutch/Flemish cattle improvement co-operative CRV (Arnhem, the Netherlands) has had an ethical committee in place since 2002. The committee advises the executive board on ethical issues, such as the application of new technologies (CRV, 2012). The committee consists of an ethicist from a university, farmers, an expert from CRV, and representatives from society. Topics such as in vitro reproduction, embryo cloning, and genome editing have been discussed in the committee. Ethical discussions start internally in CRV; thereafter, the ethical committee is consulted and, when needed, the approval or opinion of the member council of CRV is sought. A dialog with the most important stakeholder is then often initiated (S. van der Beek, CRV, Arnhem, the Netherlands; personal communication). Another active internal ethical committee can be found in the farmer-owned international pig breeding company Topigs Norsvin (Helvoirt, the Netherlands). The committee was introduced in 2005 with the task to review and evaluate various new technologies. It is seen as a necessity by the company, considering today's critical oversight from society (Coöperatie Topigs, 2015).

Moreover, several examples of codes of conduct for responsible breeding exist, one of which is the industrydriven Code-EFABAR (EFFAB, 2016). With new technologies, such codes of conducts need to be revised. Ethical discussions involving various stakeholders is a good base for revision of codes, and such discussions have been shown to be a step forward (Gamborg and Sandoe, 2005). We acknowledge that animal ethics is a wider field than animal welfare (Yeates et al., 2011); hence, breeding decisions, recommendations, and codes of conduct would benefit from an open reflection on a wide range of issues and concerns, some of which are presented in this review. We therefore propose that breeding organizations and companies take an active role in discussing the use of GM and genome editing of farm animals in a wider perspective that incorporates also ethical aspects, and thereby reassure society that ethical concerns are responsibly dealt with.

\section{ACKNOWLEDGMENTS}

The study was financed by Mistra, the Swedish Foundation for strategic environmental research (Stockholm, Sweden), together with the Swedish University of Agricultural Sciences in the research program Mistra Biotech. We are grateful to Renée Båge and Katja Nilsson (Swedish University of Agricultural Sciences) and Mickey Gjerris (University of Copenhagen, Copenhagen, Denmark) for comments on a previous version leading to considerable improvements, and we thank all colleagues for useful discussions on the topic.

\section{REFERENCES}

Ahlman, T., B. Berglund, L. Rydhmer, and E. Strandberg. 2011. Culling reasons in organic and conventional dairy herds and genotype by environment interaction for longevity. J. Dairy Sci. 94:15681575. https://doi.org/10.3168/jds.2010-3483.

AquaBounty Technologies. 2013. Review of the year. How we produce AquAdvantage ${ }^{\circledR}$ Salmon eggs. Pages $2-3$ in Annu. Report and Accounts. Accessed Mar. 28, 2017. https://www.aquabounty.com/wp -content/uploads/2014/02/How-AquAdvantage-Salmon-Eggs-are -Produced.pdf.

Arnould, V. M. R., H. Soyeurt, N. Gengler, F. G. Colinet, M. V. Georges, C. Bertozzi, D. Portetelle, and R. Renaville. 2009. Genetic analysis of lactoferrin content in bovine milk. J. Dairy Sci. 92:2151-2158. https://doi.org/10.3168/jds.2008-1255.

Arthur, P. F. 1995. Double muscling in cattle: A review. Aust. J. Agric. Res. 46:1493-1515. https://doi.org/10.3390/ani2030472.

Baranzke, H. 2002. Würde der Kreatur? Die Idee der Würde im Horizont der Bioethik. Königshausen \& Neumann, Würzburg, Germany.

Björnberg, K. E., E. Jonas, H. Marstorp, and P. Tidåker. 2015. The role of biotechnology in sustainable agriculture: Views and perceptions among key actors in the Swedish food supply chain. Sustainability 7:7512-7529. https://doi.org/10.3390/su7067512.

Blasco, A. 2008. The role of genetic engineering in livestock production. Livest. Sci. 113:191-201. https://doi.org/10.1016/j.livsci .2007.03.012.

Bruce, A. 2016a. Gene editing animals-Part of a utopian future? Pages 513-517 in Food Futures: Ethics, Science and Culture. I. A. S. Olsson, S. M. Araúju, and M. F. Vieira, ed. Wageningen Academic Publishers, Wageningen, the Netherlands. https://doi.org/ 10.3920/978-90-8686-834-6_78.

Bruce, D. M. 2016b. Genome editing: Moving the goalposts on the GM playing field? Pages 518-522 in Food Futures: Ethics, Science and Culture. I. A. S. Olsson, S. M. Araúju, and M. F. Vieira, ed. Wageningen Academic Publishers, Wageningen, the Netherlands. https://doi.org/10.3920/978-90-8686-834-6_79.

Burkard, C., S. G. Lillico, E. Reid, B. Jackson, A. J. Mileham, T. Ait-Ali, C. B. A. Whitelaw, and A. L. Archibald. 2017. Precision engineering for PRRSV resistance in pigs: Macrophages from genome edited pigs lacking CD163 SRCR5 domain are fully resistant to both PRRSV genotypes while maintaining biological function. PLoS Pathog. 13:e1006206. https://doi.org/10.1371/journal.ppat .1006206.

Carlson, D. F., C. A. Lancto, B. Zang, E.-S. Kim, M. Walton, D. Oldeschulte, C. Seabury, T. S. Sonstegard, and S. C. Fahrenkrug. 2016. Production of hornless dairy cattle from genome-edited cell lines. Nat. Biotechnol. 34:479-481. https://doi.org/10.1038/nbt.3560.

Carroll, D., A. L. Van Eenennaam, J. F. Taylor, J. Seger, and D. F. Voytas. 2016. Regulate genome-edited products, not genome editing itself. Nat. Biotechnol. 34:477-479. https://doi.org/10.1038/ nbt. 3566 .

Chastant-Maillard, S., H. Quinton, J. Lauffenburger, N. CordonnierLefort, C. Richard, J. Marchal, P. Mormede, and J. P. Renard. 2003. Consequences of transvaginal follicular puncture on well-being in cows. Reproduction 125:555-563. https://doi.org/10.1530/ rep.0.1250555.

Chen, X., Y. Yang, Z. Shi, M.-Q. Gao, and Y. Zhang. 2016. Effects of genetically modified milk containing human beta-defensin-3 on gastrointestinal health of mice. PLoS One 11:e0159700. https:// doi.org/10.1371/journal.pone.0159700.

Cooper, C. A., E. A. Maga, and J. D. Murray. 2015. Production of human lactoferrin and lysozyme in the milk of transgenic dairy animals: Past, present, and future. Transgenic Res. 24:605-614. https://doi.org/10.1007/s11248-015-9885-5.

Coöperatie Topigs. 2015. Jaarverslag 2014. Pages 1-30. Topigs Norsvin, Helvoirt. Accessed Aug. 18, 2017. http://topigsnorsvin.nl/wp -content/uploads/2015/05/2014-jaarverslag-webversie.pdf. 
Cotter, J., D. Zimmermann, and H. van Bekkem. 2015. Application of the EU and Cartagena definitions of a GMO to the classification of plants developed by cisgenesis and gene-editing techniques. Pages 1-18 in Greenpeace Research Laboratories Technical Report (Review) 07-2015. Greenpeace International Science Unit, Exeter, UK.

Cozzi, G., F. Gottardo, M. Brscic, B. Contiero, N. Irrgang, U. Knierim, O. Pentelescu, J. J. Windig, L. Mirabito, F. K. Eveillard, A. C. Dockes, I. Veissier, A. Velarde, C. Fuentes, A. Dalmau, and C. Winckler. 2015. Dehorning of cattle in the EU Member States: A quantitative survey of the current practices. Livest. Sci. 179:4-11. https://doi.org/10.1016/j.livsci.2015.05.011.

CRV. 2012. CRV and ethics - Standards and values. CRV, Arnhem, the Netherlands. Accessed Aug. 18, 2017. http://www.crv4all .com/wp-content/uploads/2012/10/CRV_and_ethics.pdf.

de Roos, A. P. W., B. J. Hayes, R. J. Spelman, and M. E. Goddard. 2008. Linkage disequilibrium and persistence of phase in Holstein-Friesian, Jersey and Angus cattle. Genetics 179:1503-1512. https://doi.org/10.1534/genetics.107.084301.

Dhople, V., A. Krukemeyer, and A. Ramamoorthy. 2006. The human beta-defensin-3, an antibacterial peptide with multiple biological functions. Biochim. Biophys. Acta Biomembranes 1758:1499-1512. https://doi.org/10.1016/j.bbamem.2006.07.007.

EFFAB (European Forum of Farm Animal Breeders). 2016. CodeEFABAR, the commitment to responsible breeding. Version 2014/2016. EFFAB, Wageningen, the Netherlands.

EFSA (European Food Safety Authority). 2017. Genetically modified animals. Accessed Mar. 28, 2017. http://www.efsa.europa.eu/en/ topics/topic/genetically-modified-animals.

European Commission. 2013. Animal cloning proposal. Accessed Mar. 28, 2017. http://ec.europa.eu/food/animals/welfare/other _aspects/cloning/details_en.

European Union. 1999. Pages 1-28 in Council Regulation (EC) No 1804/1999 of 19 July 1999 supplementing Regulation (EEC) No 2092/91 on organic production of agricultural products and indications referring thereto on agricultural products and foodstuffs to include livestock production. Off. J. Eur. Comm. 6.1.1.

European Union. 2010. Directive 2010/63/EU of the European Parliament and of the Council of 22 September 2010 on the protection of animals used for scientific purposes. Off. J. L 276.

FAO. 2007. Global plan of action for animal genetic resources and the Interlaken declaration. FAO, Commission on Genetic Resources for Food and Agriculture, Food and Agriculture Organization of the United Nations (FAO), Rome, Italy.

Fiems, L. O. 2012. Double muscling in cattle: Genes, husbandry, carcasses and meat. Animals (Basel) 2:472-506. https://doi.org/10 .3390/ani2030472.

Fischer, K., and C. Eriksson. 2016. Social science studies on European and African Agriculture compared: Bringing together different strands of academic debate on GM crops. Sustainability 8: https://doi.org/10.3390/su8090865.

Forabosco, F., F. L. Sundström, and L. Rydhmer. 2013. An algorithm for the identification of genetically modified animals. Trends Biotechnol. 31:272-274. https://doi.org/10.1016/j.tibtech.2013.02 .001 .

Francione, G. L. 2010. Animal welfare and the moral value of nonhuman animals. Law Culture Humanities 6:24-36. https://doi.org/10 $.1177 / 1743872109348989$.

Frewer, L. J., G. A. Kleter, M. Brennan, D. Coles, A. R. H. Fischer, L. M. Houdebine, C. Mora, K. Millar, and B. Salter. 2013a. Genetically modified animals from life-science, socio-economic and ethical perspectives: Examining issues in an EU policy context. N. Biotechnol. 30:447-460. https://doi.org/10.1016/j.nbt.2013.03 .010 .

Frewer, L. J., I. A. van der Lans, A. R. H. Fischer, M. J. Reinders, D. Menozzi, X. Zhang, I. van den Berg, and K. L. Zimmermann. 2013b. Public perceptions of agri-food applications of genetic modification - A systematic review and meta-analysis. Trends Food Sci. Technol. 30:142-152. https://doi.org/10.1016/j.tifs.2013.01 .003 .
Gamborg, C., and P. Sandoe. 2005. Sustainability in farm animal breeding: A review. Livest. Prod. Sci. 92:221-231. https://doi.org/ 10.1016/j.livprodsci.2004.08.010.

Gao, Y., H. Wu, Y. Wang, X. Liu, L. Chen, Q. Li, C. Cui, X. Liu, J. Zhang, and Y. Zhang. 2017. Single Cas9 nickase induced generation of NRAMP1 knockin cattle with reduced off-target effects. Genome Biol. 18:13. https://doi.org/10.1186/s13059-016-1144-4.

Golovan, S. P., R. G. Meidinger, A. Ajakaiye, M. Cottrill, M. Z. Wiederkehr, D. J. Barney, C. Plante, J. W. Pollard, M. Z. Fan, M. A. Hayes, J. Laursen, J. P. Hjorth, R. R. Hacker, J. P. Phillips, and C. W. Forsberg. 2001. Pigs expressing salivary phytase produce low-phosphorus manure. Nat. Biotechnol. 19:741-745. https://doi .org/10.1038/90788.

Grobet, L., L. J. R. Martin, D. Poncelet, D. Pirottin, B. Brouwers, J. Riquet, A. Schoeberlein, S. Dunner, F. Menissier, J. Massabanda, R. Fries, R. Hanset, and M. Georges. 1997. A deletion in the bovine myostatin gene causes the double-muscled phenotype in cattle. Nat. Genet. 17:71-74. https://doi.org/10.1038/ng0997-71.

Hammer, R. E., V. G. Pursel, C. E. Rexroad, R. J. Wall, D. J. Bolt, K. M. Ebert, R. D. Palmiter, and R. L. Brinster. 1985. Production of transgenic rabbits, sheep and pigs by microinjection. Nature 315:680-683. https://doi.org/10.1038/315680a0.

Hartley, S., and K. M. Millar. 2014. The challenges of consulting the public on science policy: Examining the development of European risk assessment policy for genetically modified animals. Rev. Policy Res. 31:481-502. https://doi.org/10.1111/ropr.12102.

Hathcock, J. N. 2000. The precautionary principle-An impossible burden of proof for new products. AgBioForum 3:255-258.

Heringstad, B., G. Klemetsdal, and J. Ruane. 2000. Selection for mastitis resistance in dairy cattle: A review with focus on the situation in the Nordic countries. Livest. Prod. Sci. 64:95-106. https://doi .org/10.1016/S0301-6226(99)00128-1.

Hickey, J. M., C. Bruce, A. Whitelaw, and G. Gorjanc. 2016. Promotion of alleles by genome editing in livestock breeding programmes. J. Anim. Breed. Genet. 133:83-84. https://doi.org/10.1111/jbg .12206 .

Hill, J. R. 2014. Incidence of abnormal offspring from cloning and other assisted reproductive technologies. Annu. Rev. Anim. Biosci. 2:307-321. https://doi.org/10.1146/annurev-animal-022513 $-114109$.

Houdebine, L.-M. 2009. Methods to generate transgenic animals. Pages 31-48 in Genetic Engineering in Livestock: New Applications and Interdisciplinary Perspectives. Vol. 34. M. Engelhard, K. Hagen, and M. Boysen, ed. Berlin-Brandenburg Akad Wissensch, Berlin, Germany.

Jenko, J., G. Gorjanc, M. A. Cleveland, R. K. Varshney, C. B. A. Whitelaw, J. A. Woolliams, and J. M. Hickey. 2015. Potential of promotion of alleles by genome editing to improve quantitative traits in livestock breeding programs. Genet. Sel. Evol. 47:55. https://doi.org/10.1186/s12711-015-0135-3.

Jonas, E., and D.-J. de Koning. 2015. Genomic selection needs to be carefully assessed to meet specific requirements in livestock breeding programs. Front. Genet. 6:49. https://doi.org/10.3389/fgene .2015 .00049

Kadarmideen, H. N., G. Mazzoni, Y. F. Watanabe, L. Strobech, P. S. Baruselli, F. V. Meirelles, H. Callesen, P. Hyttel, J. B. S. Ferraz, and M. F. G. Nogueira. 2015. Genomic selection of in vitro produced and somatic cell nuclear transfer embryos for rapid genetic improvement in cattle production. Anim. Reprod. 12:389-396.

Kasinathan, P., H. Wei, T. H. Xiang, J. A. Molina, J. Metzger, D. Broek, S. Kasinathan, D. C. Faber, and M. F. Allan. 2015. Acceleration of genetic gain in cattle by reduction of generation interval. Sci. Rep. 5:8674. https://doi.org/10.1038/srep08674.

Kruip, T. A. M., and J. H. G. denDaas. 1997. In vitro produced and cloned embryos: Effects on pregnancy, parturition and offspring. Theriogenology 47:43-52. https://doi.org/10.1016/S0093 $-691 \mathrm{X}(96) 00338-\mathrm{X}$

Kues, W. A., and H. Niemann. 2011. Advances in farm animal transgenesis. Prev. Vet. Med. 102:146-156. https://doi.org/10.1016/j .prevetmed.2011.04.009. 
Kuhlau, F., A. T. Höglund, K. Evers, and S. Eriksson. 2011. A precautionary principle for dual use research in the life sciences. Bioethics 25:1-8. https://doi.org/10.1111/j.1467-8519.2009.01740.x.

Laible, G., J. Wei, and S. Wagner. 2015. Improving livestock for agriculture - Technological progress from random transgenesis to precision genome editing heralds a new era. Biotechnol. J. 10:109-120. https://doi.org/10.1002/biot.201400193.

Lassen, J., and A. Jamison. 2006. Genetic technologies meet the public - The discourses of concern. Sci. Technol. Human Values 31:828. https://doi.org/10.1177/0162243905280021.

Leslie, K. E., and C. S. Petersson-Wolfe. 2012. Assessment and management of pain in dairy cows with clinical mastitis. Vet. Clin. North Am. Food Anim. Pract. 28:289-305. https://doi.org/10 .1016/j.cvfa.2012.04.002.

Lievens, A., M. Petrillo, M. Querci, and A. Patak. 2015. Genetically modified animals: Options and issues for traceability and enforcement. Trends Food Sci. Technol. 44:159-176. https://doi.org/10 1016/j.tifs.2015.05.001.

Liu, X., Y. Wang, Y. Tian, Y. Yu, M. Gao, G. Hu, F. Su, S. Pan, Y. Luo, Z. Guo, F. Quan, and Y. Zhang. 2014. Generation of mastitis resistance in cows by targeting human lysozyme gene to beta-casein locus using zinc-finger nucleases. Proc. Biol. Sci. 281:20133368 https://doi.org/10.1098/rspb.2013.3368.

Lund, V. 2006. Natural living-A precondition for animal welfare in organic farming. Livest. Sci. 100:71-83. https://doi.org/10.1016/j livprodsci.2005.08.005.

Mackay, T. F. C. 2004. The genetic architecture of quantitative traits: Lessons from Drosophila. Curr. Opin. Genet. Dev. 14:253-257. https://doi.org/10.1016/j.gde.2004.04.003.

Mc Parland, S., J. F. Kearney, M. Rath, and D. P. Berry. 2007. Inbreeding trends and pedigree analysis of Irish dairy and beef cattle populations. J. Anim. Sci. 85:322-331. https://doi.org/10.2527/ jas.2006-367.

Medugorac, I., D. Seichter, A. Graf, I. Russ, H. Blum, K. H. Goepel, S. Rothammer, M. Foerster, and S. Krebs. 2012. Bovine pollednessAn autosomal dominant trait with allelic heterogeneity. PLoS One 7:e39477. https://doi.org/10.1371/journal.pone.0039477.

Mellor, D. J. 2010. Galloping colts, fetal feelings, and reassuring regulations: Putting animal-welfare science into practice. J. Vet. Med. Educ. 37:94-100. https://doi.org/10.3138/jvme.37.1.94.

Miao, X. 2013. Recent advances in the development of new transgenic animal technology. Cell. Mol. Life Sci. 70:815-828. https://doi .org/10.1007/s00018-012-1081-7.

Mora, C., D. Menozzi, G. Kleter, L. H. Aramyan, N. I. Valeeva, K. L. Zimmermann, and G. P. Reddy. 2012. Factors affecting the adoption of genetically modified animals in the food and pharmaceutical chains. Bio-based Appl. Econ. 1:313-329. https://doi.org/10 .13128/BAE-11706.

Myhr, A. I. 2010. A precautionary approach to genetically modified organisms: Challenges and implications for policy and science. J. Agric. Environ. Ethics 23:501-525. https://doi.org/10.1007/ s10806-010-9234-x.

Nauta, W. J., A. F. Groen, R. F. Veerkamp, D. Roep, and T. Baars. 2005. Animal breeding in organic dairy farming: An inventory of farmers' views and difficulties to overcome. NJAS Wageningen J. Life Sci. 53:19-34. https://doi.org/10.1016/S1573-5214(05)80008 -9 .

Norberg, E. 2005. Electrical conductivity of milk as a phenotypic and genetic indicator of bovine mastitis: A review. Livest. Prod. Sci. 96:129-139. https://doi.org/10.3168/jds.S0022-0302(04)73256-7.

Nuffield Council on Bioethics. 2016. Genome editing: An ethical review. Pages 1-128 in Exploring Ethical Issues in Biology and Medicine. J. Montgomery, ed. Nuffield Council on Bioethics, London, UK.

Oback, B., and D. N. Wells. 2007. Cloning cattle: The methods in the madness. Adv. Exp. Med. Biol. 591:30-57. https://doi.org/10 .1007/978-0-387-37754-4_3.

Padel, S., H. Röcklinsberg, and O. Schmid. 2009. The implementation of organic principles and values in the European Regulation for organic food. Food Policy 34:245-251. https://doi.org/10.1016/j .foodpol.2009.03.008.
Pakkanen, R., and J. Aalto. 1997. Growth factors and antimicrobial factors of bovine colostrum. Int. Dairy J. 7:285-297. https://doi .org/10.1016/S0958-6946(97)00022-8.

Petersen, B., and H. Niemann. 2015. Molecular scissors and their application in genetically modified farm animals. Transgenic Res. 24:381-396. https://doi.org/10.1007/s11248-015-9862-z.

Petyim, S., R. Båge, A. Madej, and B. Larsson. 2007. Ovum pickup in dairy heifers: Does it affect animal well-being? Reprod Domest. Anim. 42:623-632. https://doi.org/10.1111/j.1439-0531 .2006.00833.x.

Philipsson, J., and B. Lindhe. 2003. Experiences of including reproduction and health traits in Scandinavian dairy cattle breeding programmes. Livest. Prod. Sci. 83:99-112. https://doi.org/10.1016/ S0301-6226(03)00047-2.

Proudfoot, C., D. F. Carlson, R. Huddart, C. R. Long, J. H. Pryor, T. J. King, S. G. Lillico, A. J. Mileham, D. G. McLaren, C. B. A. Whitelaw, and S. C. Fahrenkrug. 2015. Genome edited sheep and cattle. Transgenic Res. 24:147-153. https://doi.org/10.1007/ s11248-014-9832-x.

Pryce, J. E., and M. J. Bell. 2017. The impact of genetic selection on greenhouse-gas emissions in Australian dairy cattle. Anim. Prod. Sci. 57:1451-1456. https://doi.org/10.1071/AN16510.

Rainard, P., and C. Riollet. 2006. Innate immunity of the bovine mammary gland. Vet. Res. 37:369-400.

Rauw, W. M., E. Kanis, E. N. Noordhuizen-Stassen, and F. J. Grommers. 1998. Undesirable side effects of selection for high production efficiency in farm animals: a review. Livest. Prod. Sci. 56:1533. https://doi.org/10.1016/S0301-6226(98)00147-X.

Regan, T. 1983. The Case for Animal Rights. University of California Press Berkeley, Los Angeles.

Rippe, K. P. 2011. Würde der Kreatur aus rechtsphilosophischer Sicht. TIERethik 3:8-31.

Röcklinsberg, H., C. Gamborg, and M. Gjerris. 2014. A case for integrity: Gains from including more than animal welfare in animal ethics committee deliberations. Lab. Anim. 48:61-71. https://doi .org $/ 10.1177 / 0023677213514220$.

Rozin, P., M. Spranca, Z. Krieger, R. Neuhaus, D. Surillo, A. Swerdlin, and K. Wood. 2004. Preference for natural: instrumental and ideational/moral motivations, and the contrast between foods and medicines. Appetite 43:147-154. https://doi.org/10.1016/j.appet .2004.03.005.

Rutgers, B., and R. Heeger. 1999. Inherent worth and respect for animal integrity. Pages 41-53 in Recognizing the Intrinsic Value of Nature. M. Dol, M. van Vlissingen, S. Kasanmoentalib, T. Visser, and H. Zwart, ed. Van Gorcum, Assen, the Netherlands.

Sakurai, T., A. Kamiyoshi, H. Kawate, C. Mori, S. Watanabe, M. Tanaka, R. Uetake, M. Sato, and T. Shindo. 2016. A non-inheritable maternal Cas9-based multiple-gene editing system in mice. Sci. Rep. 6:20011. https://doi.org/10.1038/srep20011.

Sanderson, J. 2015. Who killed the EnviroPig? Assemblages, genetically engineered animals and patents. Griffith Law Rev. 24:244-265. https://doi.org/10.1080/10383441.2015.1063570.

Sandin, P. 2004. The precautionary principle and the concept of precaution. Environ. Values 13:461-475.

Sandin, P. 2017. How to label 'natural' foods: A matter of complexity. Food Ethics https://doi.org/10.1007/s41055-017-0008-2.

Seyfert, H. M., M. Henke, H. Interthal, U. Klussmann, D. Koczan, S. Natour, W. Pusch, B. Senft, U. M. Steinhoff, A. Tuckoricz, and G. Hobom. 1996. Defining candidate genes for mastitis resistance in cattle: The role of lactoferrin and lysozyme. J. Anim. Breed. Genet. 113:269-276. https://doi.org/10.1111/j.1439-0388.1996 .tb00616.x.

Siipi, H. 2013. Is natural food healthy? J. Agric. Environ. Ethics 26:797-812. https://doi.org/10.1007/s10806-012-9406-y.

Siipi, H. 2015. Is genetically modified food unnatural? J. Agric. Environ. Ethics 28:807-816. https://doi.org/10.1007/s10806-015 $-9568-5$.

Simianer, H. 2016. Genomic and other revolutions-Why some technologies are quickly adopted and others are not. Anim. Front. 6:53-58. https://doi.org/10.2527/af.2016-0008. 
Simojoki, H., P. Hyvonen, T. Orro, and S. Pyorala. 2010. High concentration of human lactoferrin in milk of rhLf-transgenic cows relieves signs of bovine experimental Staphylococcus chromogenes intramammary infection. Vet. Immunol. Immunopathol. 136:265271. https://doi.org/10.1016/j.vetimm.2010.03.017.

Smith, L. C., J. Therrien, F. Filion, F. Bressan, and F. V. Meirelles. 2015. Epigenetic consequences of artificial reproductive technologies to the bovine imprinted genes SNRPN, H19/IGF2, and IGF2R. Front. Genet. 6:58. https://doi.org/10.3389/fgene.2015 .00058 .

Spurlock, D. M., M. L. Stock, and J. F. Coetzee. 2014. The impact of 3 strategies for incorporating polled genetics into a dairy cattle breeding program on the overall herd genetic merit. J. Dairy Sci. 97:5265-5274. https://doi.org/10.3168/jds.2013-7746.

Stock, M. L., S. L. Baldridge, D. Griffin, and J. F. Coetzee. 2013. Bovine dehorning assessing pain and providing analgesic management. Vet. Clin. North Am. Food Anim. Pract. 29:103-133. https://doi.org/10.1016/j.cvfa.2012.11.001.

Stroebech, L., G. Mazzoni, H. S. Pedersen, K. K. Freude, H. N. Kadarmideen, H. Callesen, and P. Hyttel. 2015. In vitro production of bovine embryos: Revisiting oocyte development and application of systems biology. Anim. Reprod. 12:465-472.

Swiss Academy of Medical Sciences and Swiss Academy of Sciences. 2005. Ethical Principles and Guidelines for Experiments on Animals. 3rd ed. Accessed Aug. 15, 2017. http://www .akademien-schweiz.ch/en/dms/E/Publications/Guidelines-and -Recommendations/e_RL_Tierethik.pdf.

Tait, J. 2001. More Faust than Frankenstein: The European debate about the precautionary principle and risk regulation for genetically modified crops. J. Risk Res. 4:175-189. https://doi.org/10 $.1080 / 13669870010027640$

Tan, W., C. Proudfoot, S. G. Lillico, and C. B. A. Whitelaw. 2016. Gene targeting, genome editing: From Dolly to editors. Transgenic Res. 25:273-287. https://doi.org/10.1007/s11248-016-9932-x.

Tenbült, P., N. K. de Vries, E. Dreezens, and C. Martijn. 2005. Perceived naturalness and acceptance of genetically modified food. Appetite 45:47-50. https://doi.org/10.1016/j.appet.2005.03.004.

Thompson-Crispi, K., H. Atalla, F. Miglior, and B. A. Malian. 2014. Bovine mastitis: Frontiers in immunogenetics. Front. Immunol. 5:493. https://doi.org/10.3389/fimmu.2014.00493.

Tian, J., B. C. Bryksa, and R. Y. Yada. 2016. Feeding the world into the future -Food and nutrition security: The role of food science and technology. Front. Life Sci. 9:155-166. https://doi.org/10 $.1080 / 21553769.2016 .1174958$

Urrego, R., N. Rodriguez-Osorio, and H. Niemann. 2014. Epigenetic disorders and altered gene expression after use of assisted reproductive technologies in domestic cattle. Epigenetics 9:803-815. https://doi.org/10.4161/epi.28711.

US FDA (Food and Drug Administration). 2015. FDA takes several actions involving genetically engineered plants and animals for food. Accessed March 28, 2017. http://www.fda.gov/NewsEvents/ Newsroom/PressAnnouncements/ucm473249.htm.

van Haperen, P. F., B. Gremmen, and J. Jacobs. 2012. Reconstruction of the ethical debate on naturalness in discussions about plantbiotechnology. J. Agric. Environ. Ethics 25:797-812. https://doi .org/10.1007/s10806-011-9359-6.

van Wagtendonk-de Leeuw, A. M. 2006. Ovum pick-up and in vitro production in the bovine after use in several generations: A 2005 status. Theriogenology 65:914-925. https://doi.org/10.1016/ j.theriogenology.2005.09.007.

Wall, R. J., D. E. Kerr, and K. R. Bondioli. 1997. Transgenic dairy cattle: Genetic engineering on a large scale. J. Dairy Sci. 80:22132224. https://doi.org/10.3168/jds.S0022-0302(97)76170-8.

Wang, Z. 2015. Genome engineering in cattle: Recent technological advancements. Chromosome Res. 23:17-29. https://doi.org/10.1007/ s10577-014-9452-6.

Wei, J., S. Wagner, D. Lu, P. Maclean, D. F. Carlson, S. C. Fahrenkrug, and G. Laible. 2015. Efficient introgression of allelic variants by embryo-mediated editing of the bovine genome. Sci. Rep. 5:11735. https://doi.org/10.1038/srep11735.

Weimer, M. 2010. Applying precaution in EU authorisation of genetically modified products - Challenges and suggestions for reform. Eur. Law J. 16:624-657. https://doi.org/10.1111/j.1468-0386.2010 .00526.x.

Wickson, F., R. Binimelis, and A. Herrero. 2016. Should organic agriculture maintain its opposition to GM? New techniques writing the same old story. Sustainability 8:1105. https://doi.org/10.3390/ su8111105.

Wilmut, I., A. E. Schnieke, J. McWhir, A. J. Kind, and K. H. S. Campbell. 1997. Viable offspring derived from fetal and adult mammalian cells. Nature 385:810-813. https://doi.org/10.1038/ $385810 \mathrm{a} 0$.

Windig, J. J., R. A. Hoving-Bolink, and R. F. Veerkamp. 2015. Breeding for polledness in Holstein cattle. Livest. Sci. 179:96-101. https://doi.org/10.1016/j.livsci.2015.05.021.

Wolt, J. D., K. Wang, and B. Yang. 2016. The regulatory status of genome-edited crops. Plant Biotechnol. J. 14:510-518. https://doi .org/10.1111/pbi.12444.

Yeates, J. W., H. Röcklinsberg, and M. Gjerris. 2011. Is welfare all that matters? A discussion of what should be included in policymaking regarding animals. Anim. Welf. 20:423-432.

Zerbini, F., I. Zanella, D. Fraccascia, E. Koenig, C. Irene, L. F. Frattini, M. Tomasi, L. Fantappie, L. Ganfini, E. Caproni, M. Parri, A. Grandi, and G. Grandi. 2017. Large scale validation of an efficient CRISPR/Cas-based multi gene editing protocol in Escherichia coli. Microb. Cell Fact. 16:68. https://doi.org/10.1186/s12934-017 -0681-1. 